\title{
Pleurodesis in the treatment of pneumothorax and pleural effusion
}

\author{
P.M. Rodríguez Suárez, J.L. Freixinet Gilart
}

ABSTRACT: Pleurodesis in the treatment of pneumothorax and pleural effusion. P.M. Rodríguez Suárez, J.L. Freixinet Gilart.

Malignant pleural effusion and persistent and/or recurrent spontaneous pneumothorax are clinical entities requiring pleurodesis to avoid the accumulation of liquid and air, respectively. The objectives are to alleviate symptoms (dyspnea, pain and cough), decrease prolonged air leak, avoid recurrence and improve quality of life. Chemical pleurodesis utilizes chemical irritants. The most common of these is "talc" because of its efficiency and its success in lowering the rate of recurrence. Its main indication is in the palliative treatment of malignant pleural effusion. Other substances less frequently used because they are rarely used currently or under study are cytostatics, an- tibiotics, antiseptics and autologous blood. Surgical pleurodesis with mechanical abrasion by videothoracoscopy is indicated primarily in the treatment of spontaneous pneumothorax because it is highly efficient, easy to carry out, and has low morbidity when compared to pleurectomy. Using pleurodesis in benign effusion is highly controversial. Its principal indications are hepatic hydrothorax, chylothorax, and cardiac effusion that does not respond to medical treatment. Plasma determinations of systemic inflammatory markers and thoracic ultrasound studies can evaluate the efficacy of pleurodesis. We do not recommend the use of non-steroidal anti-inflammatory drugs in the postoperative period to avoid the possibility of interfering with hemostasis or the formation of adherences. Monaldi Arch Chest Dis 2013; 79: 2, 81-86.

Keywords: Malignant effusion, Pneumothorax, Pleurodesis, Talc, Pleural abrasion, Thoracoscopy.

Servicio de Cirugía Torácica, Hospital Universitario de Gran Canaria “Dr. Negrín”, Las Palmas de Gran Canaria, España.

Correspondence: Dr. Pedro Miguel Rodríguez Suárez, Servicio de Cirugía Torácica, Hospital Universitario de Gran Canaria "Dr. Negrín”, C/ Barranco de la Ballena s/n, 35010 Las Palmas, España; e-mail:prosu2001@yahoo.es

\section{Introduction}

The term pleurodesis comes from the Greek pleura-desis and consists of the fusion of both pleural sheets (parietal and visceral). Pleurodesis dates back to the beginnings of thoracic surgery [1]. In order to obtain this objective, different techniques have been employed, such as the instillation of products (chemical or medical pleurodesis) or surgical techniques (mechanical or surgical pleurodesis). The ideal sclerosing agent should be low-cost, readily available, easy to use, relatively free of side effects, and highly efficient [2]. Chemical pleurodesis stands out because it is easy to carry out, has a great variety of sclerosing agents and has been proven effective. Surgical pleurodesis is a mechanical aggression of the parietal pleura to achieve the desired effect.

The efficiency of pleurodesis is shown by its control of clinical symptoms (progressive dyspnea, pleural pain and cough), pulmonary re-expansion in radiological studies (simple radiography of the thorax and CT), and a decrease in recurrences $[1,3]$. Thoracic ultrasound studies have shown to be very sensitive when evaluating the effectiveness of pleurodesis [4]. Measurements of systemic inflammatory markers such as CRP, leukocyte count or erythrocyte sedimentation rate could help in assessing the effectiveness of pleurodesis [2].

\section{Indications for pleurodesis}

The aim of pleurodesis is to obliterate the pleural space in order to prevent the accumulation of air or liquid, alleviate or control symptoms and avoid relapse. There are two clinical entities that, because of their frequency and tendency to relapse, benefit from pleurodesis: pleural effusion and pneumothorax.

\section{Pleural Effusion}

Pleural effusion is very frequent in daily clinical practice. It has multiple etiologies and, at times, difficult to manage therapeutically because of its frequent rate of recurrence. The entities for which it is indicated are, by order of frequency, malignant pleural effusion (MPE) and persistent and/or recurrent benign effusion that does not respond to treatment [3]. MPE represents at least $90 \%$ of the indications for chemical pleurodesis and is usually an advanced stage of any cancer pathology. It occurs most commonly in pulmonary, mammary, ovarian cancers, lymphoma and mesothelioma [5]. Its indication is to relieve symptoms (progressive dyspnea, pleural pain and cough), avoid relapse, and improve quality of life. In case of mesothelioma, the pleurodesis can also be performed with curative intent, before pleurec- 
tomy and pleuro-pneumonectomy. Pleurodesis for benign pleural effusion is controversial given that effusion is the consequence of some pathology, generally extra-thoracic. The principal entities that benefit from this technique are hepatic hydrothorax, cardiac insufficiency and chylothorax. It should be used for patients with frequent relapses and/or patients who have not responded well to medical treatment [3].

\section{Pneumothorax}

Pneumothorax is defined as the presence of air in the pleural cavity. The origin can be spontaneous (SP) or acquired (AP). The main issues raised are the tendency to relapse or prolonged air leak [6]. Pleurodesis in the treatment of SP is indicated in cases of persistent air leak (greater than 57 days), recurrence or lack of lung re-expansion. The main cause of lack of lung reexpansion is the presence of pleuropulmonary adhesions. Generally, the surgical technique involves resection of affected lung parenchyma (blebs, bullae), pleuropulmonary adhesions release and pleurodesis, chemical or mechanical $[6,7]$.

\section{Chemical pleurodesis}

Chemical pleurodesis is the intrapleural application of a chemical irritant, either through a chest tube or via thoracoscopy (VTS). Sterile talc is the most commonly used agent [2], although there are other substances such as antibiotics (tetracycline hydrochloride, minocycline, doxycycline), cyto- static agents (bleomycin, cisplatin); antiseptics (iodine povidone) and autologous blood. For this technique to be effective, it is imperative that pulmonary expansion is achieved after thoracentesis [2]. Chemical pleurodesis is also used for SP, though not as frequently as in effusion, and especially for inoperable patients. Its utilization in primary SP is less controversial than in secondary SP. Some authors affirm that the use of talc is not recommended because it could aggravate underlying pulmonary fibrosis [8]. The main characteristics are shown in table 1.

\section{Talc (Hydrated magnesium trisilicate)}

Talc is considered the best pleurodesic substance because of its effective sclerosing, ease of use, availability, lack of side effects and low cost [2]. When used medically, it should be free of asbestos and sterilized [9]. In addition, a composition of medium-sized particles $(25 \mu \mathrm{m})$ with at least $10 \%$ of particles less than $10 \mu \mathrm{m}$ to avoid absorption and the appearance of adverse systemic effects. After pleural instillation, talc produces an activation of mesothilial cells and an intense inflammatory response (increased interleukin 8 , decreased fibrinolysis, increased blood clotting factor, and fibroblast growth factor) $[9,11]$. This is why the use of NSAIDs could weaken the effectiveness of pleurodesis by altering the inflammatory cascade $[12,13]$. Talc contains many impurities responsible for minor adverse effects such as fever and pleuritic pain. The main problem that can occur, however, is acute respiratory distress, which

Table 1. - Characteristics of chemical pleurodesis agents

\begin{tabular}{|c|c|c|}
\hline AGENT & ADVANTAGE & DISADVANTAGE \\
\hline Sterile talc & $\begin{array}{l}\text { - Ease of use } \\
\text { - Availability } \\
\text { - Low cost }\end{array}$ & $\begin{array}{l}\text { - Fever } \\
\text { - Pleuritic pain }\end{array}$ \\
\hline Tetracycline & $\begin{array}{l}\text { - Ease of use } \\
\text { - Synergistic effects } \\
\text { with other agents }\end{array}$ & $\begin{array}{l}\text { - Poor availability } \\
\text { - Pleuritic pain } \\
\text { - Systemic side effects }\end{array}$ \\
\hline Minocycline & $\begin{array}{l}\text { - Synergistic effects } \\
\text { with other agents }\end{array}$ & $\begin{array}{l}\text { - Pleuritic pain } \\
\text { - Respiratory distress }\end{array}$ \\
\hline Doxycycline & - Repeated doses & $\begin{array}{l}\text { - Pleuritic pain } \\
\text { - Fever } \\
\text { - Cough }\end{array}$ \\
\hline Bleomycin & - Antineoplasic effect & $\begin{array}{l}\text { - Pleuritic pain } \\
\text { - Fever } \\
\text { - Nausea and vomiting }\end{array}$ \\
\hline Iodine povidone & $\begin{array}{l}\text { - Easily available } \\
\text { - Low-cost }\end{array}$ & $\begin{array}{l}\text { - Pleuritic pain } \\
\text { - Hypotension } \\
\text { - Fever } \\
\text { - Empyema } \\
\text { - Acute respiratory distress }\end{array}$ \\
\hline Autologous blood & - Avoids toxic systemic effects & $\begin{array}{l}\text { - Empyema } \\
\text { - Chest tube obstruction }\end{array}$ \\
\hline
\end{tabular}


can be fatal in $1 \%$ of the cases [2]. In general, the quantity of talc used depends on the pathology: for malignant pleural effusion, $4 \mathrm{~g}$ and in pneumotho$\operatorname{rax}, 2 \mathrm{~g}$.

The technique for instilling talc in the pleural cavity can be:

- Dry Powder Spray ("talc poudrage"): distribution of dry talc in the pleural cavity by VTS (most employed), or by thoracotomy under sedation or general anesthesia. Dry talc instillation can be carried out manually, mechanically or pressurized. Its most frequent indication is the palliative treatment of MPE, 78-96\% efficient, achieving $60 \%$ complete immediate lung expansion and a relapse rate of $10 \%$ in the first month [14]. For patients with an acceptable clinical situation and a lack of definitive histological diagnosis, VTS allows the pleural biopsy, intraoperative histological analysis and pleurodesis in case of malignancy at the same time [14]. VTS pleurodesis with dry talc for the treatment of primary SP is easy to carry out, efficient, safe, quick, has a low morbidity rate (3\%-9\%), no mortality, and a recurrence rate of $3 \%$, even lower than VTS mechanical abrasion $[15,16]$. Its most frequent side effects are pain (pressurized form the most serious) and disthermia. The most serious and undesirable side effect is acute respiratory distress syndrome [1]. As to long-term adverse effects, results in the literature are controversial. Younger patients with SP, the formation of foreign body granulomas and the potential deterioration of pulmonary function make its use very controversial for many groups. Nevertheless, studies with follow-up at five years show no sequelae from its use [17-19].

- Instillation in suspension ("talc slurry"): in use since 1958, it consists of instilling the talc in a suspended form in order to mix dry talc with saline (most frequent) or with iodine povidone to increase its sclerosing power. Afterward, it is introduced into the pleural cavity through a catheter or drainage tube. In the treatment of MPE, the efficiency varies between $71 \%$ and $90 \%$, although the full degree of pulmonary expansion is less than with the spray technique $[5,10,20]$. We can deduce that the degree of pulmonary re-expansion does not correlate linearly with relapse, clinical efficiency or complications [11]. The principal indication is MPE with good clinical and/or radiological response to thoracentesis, but with serious general deterioration and/or elevated surgical risk [5]. Experience in treating primary SP is minimal because VTS is used. In patients with secondary SP and high surgical risk, pleurodesis with talc slurry is a valid alternative to spray by VTS, with a failure rate of $28.1 \%$ promoted by pneumopathy, the need for mechanical ventilation, and persistent air leaks [21]. Pain is the most common side effect $(37.5 \%)$ and it is more frequent in patients who receive more than $5 \mathrm{~g}$ of talc. Respiratory distress is infrequent $(1.6 \%)$ [2, 15, 16].

\section{Tetracycliness}

Although tetracycline was the most used agent in the 1980 's, its poor availability in many countries in subsequent years caused it to fall into disuse $[22,23]$. The recommended dosage is $500 \mathrm{mg}$ diluted in $100 \mathrm{cc}$ of saline solution and administered through pleural drainage. In the treatment of $\mathrm{SP}$, its effectiveness is $63.6 \%$, much lower if compared to talc slurry (84.2\%). In the management of MPE, and to increase its efficiency and decrease relapses, it can be combined with other pleurodesic agents such as bleomycin. In this way, an efficiency of up to $70 \%$ and a recurrence rate of $25 \%$ can be obtained [24]. Its most undesirable and frequent side effect is intense pleuritic pain. Its pleural absorption capacity can also provoke systemic alterations such as hepatic insufficiency, which has caused it to fall out of use.

\section{Minocycline}

Minocycline is a derivative of tetracycline, which induces fibrosis in the pleural cavity. It can be administered by VTS or through a drainage tube. Its most frequent indication is the closing of air leaks in SP [2]. The recommended dosage is $300 \mathrm{mg}$ diluted in a $20 \mathrm{ml}$ saline solution, and its efficiency is about $80 \%$ initially [25]. Studies done with ultrasound 30 days after pleurodesis for SP have shown that minocycline by VTS is better than mechanical abrasion in terms of lowering air leaks (5\% vs 2\%) and degree of obliteration of the pleural cavity (96\% vs 93\%) [4]. It also has a synergistic effect with mechanical abrasion and induces a more effective pleurodesis than when these techniques are used separately. Its most frequent adverse effect is pleuritic pain $(44.6 \%)$, and the most serious is respiratory distress $(1.7 \%)$ [2].

\section{Doxycycline}

To achieve a good result, instillations must be repeated several times to reach an efficiency of $70 \%$. The usual dosage is between $500 \mathrm{mg}$ and $1 \mathrm{~g}$, diluted in $50 \mathrm{cc}$ saline. Adverse effects appear in up to $81 \%$ of the cases. Moderate to severe pleuritic pain $(60 \%)$, fever $(30 \%)$, and cough $(3 \%)$ stand out. It is used in the treatment of MPE, although there is some experience of its use in benign effusion and pneumothorax.

\section{Autologous blood}

This is a technique described by Robertson and employed since 1987. Autologous blood is introduced into the pleural cavity in order to seal off prolonged air leaks in spontaneous pneumothorax or after pulmonary resection [29]. This blood irritates both pleural surfaces and induces the formation of a fibrin plug that adheres to the surface of the lung, sealing off air loss. The technique involves the immediate administration of between 50 and $150 \mathrm{ml}$ of autologous venous blood without coagulants into the pleural cavity through pleural 
drainage. The drainage is maintained, non aspirative, for 2-3 hours while the patients performs movements to ensure the best distribution. It can be repeated several times with an efficiency of between $75 \%-84 \%[30,31]$. Its major advantages are that it avoids possible toxic systemic effects of cytostatic pleurodesic agents, shortens the duration of air leaks, and does not affect respiratory function. Its most frequent complications arise from the technique itself, and include pleural empyema and obstruction of the chest tube by blood clots [32-34].

\section{Bleomycin}

Anti-neoplastic agents have been used since the 1960's for the treatment of MPE [2]. Bleomycin is a frequently-used cytostatic agent because of its pleural fibrosing and anti-neoplastic effect. The most commonly used dosage is $60 \mathrm{IU}$ in $50 \mathrm{cc}$ saline with only one application. Its most frequent side effects are pleuritic pain, fever, nausea and vomiting. Its effectiveness ranges from 35$60 \%$ and the recurrence rate increases with time up to $41 \%$ in the first month, $59 \%$ at 3 months and $65 \%$ at 6 months [35].

\section{Iodine Povidone}

Iodine Povidone is antiseptic topical based on iodine. It is easily available and low-cost. The recommended dosage is $20 \mathrm{ml}$ of $10 \%$ iodine povidone diluted in $80 \mathrm{ml}$ saline and introduced through pleural drainage or VTS. Its efficiency is $93 \%$ in the treatment of SP and 98\% in MPE [36]. The most frequent adverse effect is pleuritic pain, appearing in $13 \%-18 \%$ of the cases. Other described adverse effects are hypotension, fever, empyema and acute respiratory distress. Its use is comparable to talc slurry, but a lack of studies evaluating its systemic consequences have kept its use from becoming widespread $[37,38]$.

\section{Silver Nitrate}

Silver nitrate is a sclerosing agent that induces a caustic lesion on the pleura. Used sporadically since the 1940's for SP as well as MPE, it has fallen into disuse due to its adverse effects. The recommended dosage is $20 \mathrm{ml}, 0.5 \%$ administered through a drainage tube. The effectiveness after 4 months reaches $96 \%$. Its main adverse effects are pleuritic pain and reactive pleural effusion, probably related to concentrations over $10 \%$. It is an effective agent that requires more study in order to become an alternative to talc slurry [5].

\section{Quinacrine}

Quinacrine is an anti-malaria drug used as a sclerosing agent in some countries. The recommended dosage is $500 \mathrm{mg}$ diluted in $200 \mathrm{ml}$ saline administered through a chest tube. The efficiency $(64 \%-100 \%)$ increases in relation to the times administered. Its undesirable side effects such as pleural pain, fever, nausea and mental disorders have caused it to fall into disuse [2].

\section{Other pleurodesic substances}

Other substances that are capable of pleural symphysis include 5-fluorouracil, cisplatin, vincristine, mitomycin, interferon and quinacrine.

\section{Surgical pleurodesis}

This is carried out in surgery under general anesthesia. A lesion is made in the parietal pleura to activate an inflammatory process and create adherences between pleural layers. In the treatment of SP, this technique is performed in isolation or combined with resection of bullae and blebs of the lung parenchyma, depending on the surgical findings (Vanderschueren classification) [39]. The approach can be by VTS (most frequent) or by thoracotomy. The efficiency is over $90 \%$ and the recurrence rate with VTS is between $5 \%-10 \%$, while open surgery is $1 \%$ [7]. The reason for this is that the inflammatory reaction induced by VTS is lower than in open thoracotomy [40]. On the other hand, the risk of recurrence is higher in patients without evidence of blebs or with multiple blebs (more than 3) [7]. Mechanical pleurodesis is not usually used in the treatment of MPE. Regarding the postoperative use of non-steroidal anti-inflammatory drugs (NSAIDs), the data are contradictory. Some studies show that the systematic use of NSAIDs in the postoperative period reduces the formation of adhesions [12, 13].

There are different mechanical techniques to obtain pleurodesis.

\section{Swabs, scraper or dry gauze}

This method is widespread and used in daily clinical practice. Parietal mechanical abrasion is achieved by a direct lesion, using sterile materials such as gauze, swabs or scrapers [7, 39]. VTS is most frequently used, although open surgery can also be done. This irritation is effective when the appearance of a mottled hemorrhagic petechiae or mild bleeding from the parietal pleura are noticed. Its main indication is in the treatment of SP with a morbidity reaching $6.25 \%$ (persistent air leaks, hemothorax) and a recurrence of between $6.2 \%-9.8 \%$ $[7,39,41]$. A modification of this technique is using a sponge or a swab soaked in an aqueous solution of $35 \%$ dextrose. Using electric rotary brushes to create the abrasion has also been described [42].

\section{Pleural cauterization by electrocautery, laser}

Pleural lesions can be done by electrocautery and less frequently by laser, avoiding the risk of bleeding from abrasive techniques.

\section{Partial or total pleurectomy}

Pleurectomy involves the excision of the parietal pleura located in the thoracic dome above the 
$6^{\text {th }}$ costal arch. Compared to mechanical abrasion, it increases operating time and produces a large amount of intra- and postoperative blood loss (hemothorax) which results in an $8 \%$ rate of re-intervention. This is significantly higher than with mechanical abrasion [7]. The efficiency of the technique is similar to that of mechanical abrasion, but there are fewer recurrences: $0 \%-4.6 \%$ with VTS and $0 \%-1 \%$ with thoracotomy $[43,44]$. Residual pain and discomfort is also higher with pleurectomy than with abrasion, probably due to more intercostal damage [7]. On the other hand, there are no differences in hospital stay, duration of drainage and pulmonary function.

\section{Combined pleurodesis}

Various techniques can be combined to increase the effectiveness and decrease recurrences. Most notable is VTS mechanical pleural abrasion with an immediate postoperative instillation of minocycline through chest tube. Compared to videothoracoscopic apical pleurectomy, its efficiency is similar in terms of drainage time, hospital stay, complications and relapses (3.8\%) [25].

\section{Conclusions}

Pleurodesis with talc spray by VTS is the technique of choice in the treatment of MPE, reserving talc slurry for patients with serious deterioration of general health or high surgical risk. Pleurodesis by mechanical abrasion has proved to be efficient, easy and safer in the treatment of recurrent or persistent SP than pleurectomy, although pleurectomy has fewer recurrences. Continued study is necessary to determine inflammatory plasma parameters related to pleurodesis. Studies with thoracic ultrasound are very sensitive in the evaluation of pleurodesis.

\section{References}

1. Bethune N. Pleural poudrage: new techniques for deliberate production of pleural adhesions as preliminary to lobectomy. J Thorac Surg 1935; 4: 251-61.

2. Dikensoy O, Light RW. Alterantive widely available, inexpensive agents for pleurodesis. Curr Opin Pulm Med 2005; 11: 340-344.

3. Bouros D, Froudarakis M, Siafakas NM. Pleurodesis. Everything Flows. Chest 2000; 118: 577-9.

4. Alayouty HD, Hasan TM, Alhadad ZA, Omar Barabba R. Mechanical versus chemical pleurodesis for management of primary spontaneous pneumothorax evaluated with thoracic echography. Interact Cardiovasc Thorac Surg 2011; 13: 475-9.

5. Genestreti G, Moretti A, Piciucchi S, et al. FDG PET/CT Response Evaluation in Malignant Pleural Mesothelioma Patients Treated with Talc Pleurodesis and Chemotherapy. J Cancer 2012; 3: 241-5.

6. Mármol Cazas EE, Martínez Somolinos S, Baldó Padró X, Rubio Garay MM, Penagos Tafurt JC, Sebastián Quetglás F. Efficacy, morbidity and mortality of surgical treatment of a primary spontaneous pneumothorax by videothoracoscopic talc pleurodesis. Cir Esp 2011; 89: 463-7.

7. Jin-Shing Chen, Hsao-Hsun Hsu, Pei-Ming Huang, et al. Thoracoscopic pleurodesis for primary spontaneous pneumothorax with high recurrence risk: a prospective randomized trial. Ann Surg 2012; 255: 440-445.

8. $\mathrm{Ng} \mathrm{CK}$, Ko FW, Chan JW, et al. Minocycline and talc slurry pleurodesis for patients with secondary spontaneous pneumothorax. Int J Tuberc Lung Dis 2010; 14: 1342-6.

9. Weissberg D. Talc pleurodesis: a controversial issue. Poumon-Coeur 1981; 37: 291-4.

10. Ferrer J, Villarino MA, Tura JM, Traveria A, Light RW. Talc preparations used for pleurodesis vary markedly from one preparation to another. Chest 2001; 119: 1901-5.

11. Kennedy L, Vaughan LM, Steed LL, Sahn SA. Sterilization of talc for pleurodesis. Available techniques, efficacy, and cost analysis. Chest 1995; 107: 1032-4.

12. Hunt I, Teh E, Southon R. Using non-steroidel anti-inflammatory drugs (NSAIDS) following pleurodesis. Interact Cardiovasc Thoracic Surg 2007; 6; 102-4.

13. Ben-Nun A, Golon N, Faibishenko I. Nonsteroidal anti-inflammatory medications: efficient and safe treatment following video-assisted pleurodesis for spontaneous pneumothorax. World J Surg 2011; 35: 2563-7.

14. Mingarini Terra R, Machado Junqueira JM, Ribeiro Teixeira L, Suso Vargas F, Pego-Fernándes PM, Biscegli Jatene F. Is full postpleurodesis lung expansión a determinant of a successful outcome after talc pleurodesis? Chest 2009; 136: 361-368.

15. Ramos-Izquierdo R, Moya J, Macia I, et al. Treatment of primary spontaneous pneumothorax by videothoracoscopic talc pelurodesis under local anesthesia: a review of 133 procedures. Surg Endosc 2010; 24: 984-7.

16. Cardillo G, Carleo F, Giunti R, et al. Videothoracoscopic talc poudrage in primary spontaneous pneumothorax: a single institution experience in 861 cases. J Thorac Cardiovasc Surg 2006; 131: 322-8.

17. Lange P, Mortensen J, Froth S. Lung function 22-35 years after treatment of idiopathic spontaneous pneumothorax with talc Poudrage or simple drainage. Tho$\operatorname{rax} 1988$; 43: 559-561.

18. Sepehripour AH, Nasir A, Shah R. Does mechanical pleurodesis results in better outcomes than chemical pleurodesis for recurrent primary spontaneous pneumothorax? Interact Cardiovasc Thorac Surg 2012; 14: 307-11.

19. De Campos JR, Vargas FS, De Campos Werebe E, Cardoso P, Teixeira LR, Jatene FB. Thoracoscopy talc poudrage: a 15-year experience. Chest 2001; 119: 801-6.

20. Ong KG, Indumathi V, Raghuram J, Ong YY. A comparative study of pleurodesis using talc slurry and bleomycin in the management of malignant pleural effusions. Respirology 2000; 5: 99-103.

21. Yim APC, Chan ATC, Lee TW, et al. Thoracoscopic talc insuflaion versus talc slurry for symptomatic malignant pleural effusion. Ann Thorac Surg 1996; 62: 1655-165.

22. Emad A, Rezaian GR. Treatment of malignant pleural effusions with a combination of bleomycin or tetracycline alone versus a combination of bleomycin and tetracycline. Cancer 1996; 78: 2498-501.

23. Sahn SA, Good JT. The effect of common sclerosing agents on the rabbit pleural space. Am Rev Respir Dis 1981; 124: 65-67.

24. Emad A, Rezaian GR. Treatment of malignant pleural effusions with a combination of bleomycin or tetracycline alone versus a combination of bleomycin and tetracycline. Cancer 1996; 78: 2498-501.

25. Chen JS, Tsai KT, Hsu HH. Intrapleural minocycline following simple aspiration for initial treatment of primary spontaneous pneumothorax. Respir Med 2008; 102: 1004-1010.

26. Harrington JD, Gora-Harper ML, Salley RK. Chemical pleurodesis with doxycycline 1 g. Pharmacotherapy 1996; 16: 280-5. 
27. Mitchem RE, Herndon BL, Fiorella RM, Molteni A, Battie CN, Reisz GR. Pleurodesis by autologous blood, doxycycline, and talc in a rabbit model. Ann Thorac Surg 1999; 67: 917-21.

28. Pulsiripunya C, Yougchaiyud P, Pushpakom R, Maranetra N, Nana A, Charoenratanakul S. The efficacy of doxyxycline as a pleural sclerosing agent in malignant pleural effusion: a prospective study. Respirology 1996; 1: 69-72.

29. Cobanoglu U, Melek M, Edirme Y. Autologous blood pleurodesis: a good choice $\mathrm{n}$ patients with persistent air leak. Ann Thorac Med 2009; 4: 182-6.

30. Blanco Blanco I, Canto Argiz H, Carro del Camino F, Fuentes Vigil J, Sala Blanco J. Pleurodesis con sangre autóloga. Resultados iniciales en 14 casos. Arch Bronconeumol 1996; 32: 230-6

31. Blanco Blanco I, Sala Blanco J, Cantó Argiz H, Carro del Camino F, Gorostidi Pérez J. Pleurodesis con sangre autóloga. Resultados de una serie de 17 casos con más de un año de seguimiento. Rev Clin Esp 1997; 197: 406-10.

32. Cagirici U, Sahin B, Cakan A, Kabayas H, Budunelli T. Autologus blood patch pleurodesis in spontaneous pneumothorax with persistent air leak. Scand Cardiovasc J 1998; 32: 75-8.

33. Williams P, Laing R. Tension pneumothorax complicating autologous "blood patch" pleurodesis. Thorax 2005; 60: 1066-1067.

34. Karangelis D, Tagarakis GI, Daskalopoulos M, et al. Intrapleural instillation of autologous blood for persistent air leak in spontaneous pneumothorax-is it as effective as it is safe? J. Cardiothorac Surg 2010; 5: 61.

35. Vargas FS, Wang NS, Lee HM. Effectiveness of bleomycin in comparison to tetracycline as pleural sclerosing agent in rabbits. Chest 1993; 104: 1582-1584.
36. Neto JD, De Oliveira SF, Vianna SP, Terra RM. Efficacy and safety of iodopovidone pleurodesis in malignant pleural effusions. Respirology 2010; 15: 115-8.

37. Mahmodlou R, Rahimi-Rad MH, Alizadeh H. Efficacy and safety of iodopovidone pleurodesis through chest tube in spontaneous pneumothorax. Pneumologia 2011; 60: 78-80.

38. Agarwal R, Paul AS, Aggarwal AN, Gupta D, Jindal SK. A randomized controlled trial of the efficacy of cosmetic talc compared with iodopovidone for chemical pleurodesis. Respirology 2011; 16; 1064-9.

39. Rena O, Massera F, Papalia E, Della Pona C, Robustellini M, Casadio C. Surgical pleurodesis for Vanderschueren's stage III primary spontaneous pneumothorax. Eur Respir J 2008; 31: 837-841.

40. Gebhard FT, Becker HP, Gerngross H. Reduced inflammatory response in minimally invasive surgery of pneumothorax. Arch Surg 1996; 131: 1079-1082.

41. Chen JS, Hsu HH, Chen RJ. Additional minocycline pleurodesis after thoracoscopic surgery for primary spontaneous pneumothorax. Am J Respir Crit Care Med 2006; 173: 548-554.

42. Maier A, Anegg U, Renner H, Tomaselli F, Fell B, Lunzer R. Four-year experience with pleural abrasion using a rotating brush during video-assisted thoracoscopy. Surg Endosc 2000; 14: 75-8.

43. Chang YC, Chen CW, Huang SH. Modified needlescopic video-assisted thoracic surgery for primary spontaneous pneumothorax: the long-term effects of apical pleurectomy versus pleural abrasion. Surg Endosc 2006; 20: 757-762.

44. Casadio C, Rena O, Giobbe R, Rigone R, Maggi G, Oliaro A. Stapler blebectomy and pleural abrasion by video-assisted thoracoscopy for spontaneous pneumothorax. J Cardiovasc Surg 2002; 43: 259-62.

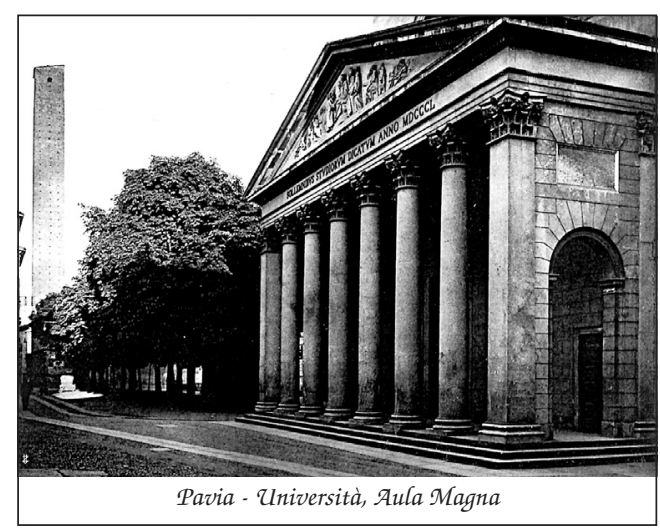

